\title{
Performance Check of a Wavelength Dispersive X-Ray Spectrometer (WDS) attached to the SEM
}

\author{
V.-D. Hodoroaba* and M. Procop** \\ * Federal Institute for Materials Research \& Testing (BAM), D-12205 Berlin, Germany \\ ** IfG - Institute for Scientific Instruments, D-12489 Berlin, Germany
}

Besides energy dispersive spectrometers (EDS) that complete most of the scanning electron microscopes (SEM) there is an increasing number of wavelength dispersive spectrometers (WDS) that are attached to a SEM $[1,2]$. Hence, the analytical facilities available with a SEM are extended towards better element sensitivities and peak separation.

Procedures for a periodical check of the performance of the WDS attached to a SEM are less established than in the case of EDS. For accredited laboratories such procedures are even mandatory. Of primary interest is the stability of the peak count rate as a measure of the accurate operation of the gas flow proportional counter (stability of the composition/flow rate of the carrier gas), accurate mechanical adjustment of the whole "WDS geometry" (diffraction crystals, sample and whole spectrometer positioning) and the long-term stability of the transmission of the hybrid X-ray optics used. Spectrometer resolution (FWHM) and calibration of the energy scale are also considered.

In this paper the results of the periodical performance check of a parallel beam spectrometer (PBS) at a SEM over a longer period of time are presented. The check includes the measurement of FWHM, the intensity in counts per $\mathrm{nA}$ and the peak-to-background ratio. In opposite to the performance check of an EDS [3] this has been proven to be more laborious, not only more timeconsuming, but also "tricky". Especially the exact mechanical alignment of the whole "WDS geometry" and its implications for the WDS quantification will be highlighted in this work.

Conventionally, a set of several specimens is used to perform the measurements with the diffraction crystals. We currently use a single test material specially developed at BAM (EDS-TM001) for these purposes [4]. It consists of five elements carbon, aluminum, manganese, copper and zirconium homogeneously distributed in a thick layer (ca. $10 \mu \mathrm{m})$ on a steel substrate, see Figure 1. X-ray lines of energies covering representatively the whole energy rangy of the five or six diffractors of the WDS are hence available in one specimen only (e.g. from $\mathrm{Zr}-\mathrm{M} \zeta$ at $0.152 \mathrm{keV}$ (!) up to $\mathrm{Cu}-\mathrm{K} \beta$ at $8.904 \mathrm{keV}$ ), see Table 1. Therefore, the whole check procedure becomes less time-consuming and delivers more reliable results. Some representative X-ray line maps are presented in Figure 2.

\section{References}

[1] D. Redfern, A. Sandborg, Microsc. Microanal. 11 (Suppl 2) (2005) 468.

[2] C. van Hoek, M. Koolwijk, Microchim. Acta 161 (2008) 161.

[3] M. Procop, V.-D. Hodoroaba, M. Griepentrog, Microsc. Microanal. 12 (Supp 2) (2006) 870.

[4] www.webshop.bam.de ("Reference materials" / "Test materials" / "EDS-TM001"). 
TABLE 1. Energy ranges "covered" by the diffractors existing in the commercial PBS MAXray (Thermo Fisher Scientific) and the X-ray lines "offered" by the EDS-TM001 test material for the spectrometer performance check.

\begin{tabular}{llll}
\hline Diffractor & Energy range (keV) & X-ray line & Energy of the X-ray line (keV) \\
\hline MoB4C200 & 0.066 to 0.257 & $\mathrm{Zr} \mathrm{M} \zeta$ & 0.152 \\
NiC80 & 0.167 to 0.647 & $\mathrm{C} \mathrm{K}$ & 0.286 \\
WSi60 & 0.221 to 0.857 & $\mathrm{Mn} \mathrm{L} \alpha$ & 0.645 \\
TAP & 0.509 to 1.979 & $\mathrm{Cu} \mathrm{L \alpha}, \mathrm{Al} \mathrm{K \alpha}$ & $0.930,1.489$ \\
PET & 1.509 to 5.862 & $\mathrm{Zr} \mathrm{L} \alpha$ & 2.046 \\
$\mathrm{LiF}$ & 4.633 to 17.994 & $\mathrm{Mn} \mathrm{K \alpha}, \mathrm{Cu} \mathrm{K \alpha}$ & $5.887,8.054$ \\
\hline
\end{tabular}

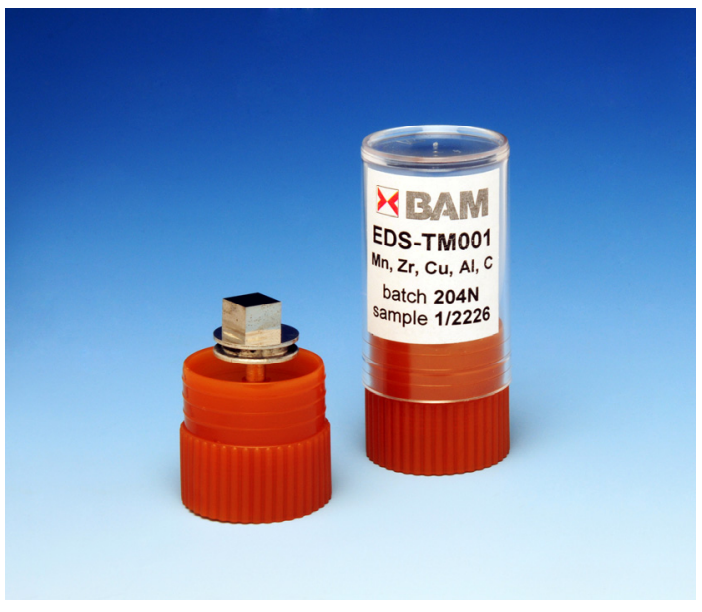

FIG. 1. Test material EDS-TM001 [4].
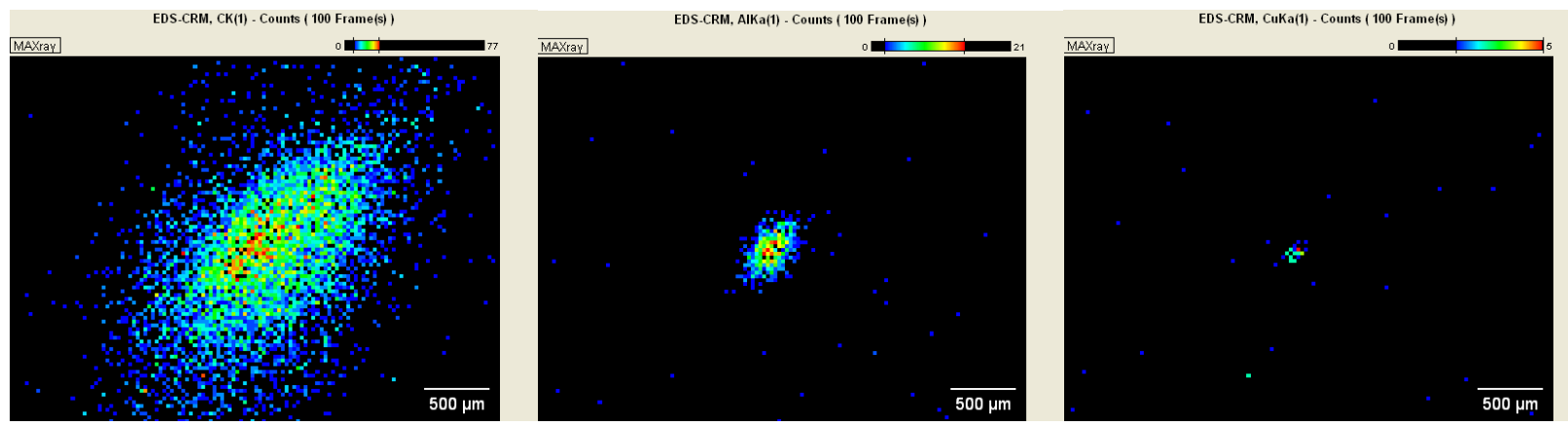

FIG. 2. Maps of some selected X-ray lines emitted by the test material EDS-TM001: C K (0.286 $\mathrm{keV}), \mathrm{Al} \mathrm{K \alpha}(1.489 \mathrm{keV})$ and $\mathrm{Cu} \mathrm{K \alpha}(8.054 \mathrm{keV})$. 